\title{
Are Government Bonds Net Wealth?
}

\section{Citation}

Barro, Robert J. 1974. Are government bonds net wealth? Journal of Political Economy 82(6): 1095-1117.

\section{Published Version}

doi:10.1086/260266

\section{Permanent link}

http://nrs.harvard.edu/urn-3:HUL.InstRepos:3451399

\section{Terms of Use}

This article was downloaded from Harvard University's DASH repository, and is made available under the terms and conditions applicable to Other Posted Material, as set forth at http:// nrs.harvard.edu/urn-3:HUL.InstRepos:dash.current.terms-of-use\#LAA

\section{Share Your Story}

The Harvard community has made this article openly available.

Please share how this access benefits you. Submit a story.

\section{Accessibility}




\title{
Are Government Bonds Net Wealth?
}

\section{Robert J. Barro}

\author{
University of Chicago
}

The assumption that government bonds are perceived as net wealth by the private sector is crucial in demonstrating real effects of shifts in the stock of public debt. In particular, the standard effects of "expansionary" fiscal policy on aggregate demand hinge on this assumption. Government bonds will be perceived as net wealth only if their value exceeds the capitalized value of the implied stream of future tax liabilities. This paper considers the effects on bond values and tax capitalization of finite lives, imperfect private capital markets, a government monopoly in the production of bond "liquidity services," and uncertainty about future tax obligations. It is shown within the context of an overlappinggenerations model that finite lives will not be relevant to the capitalization of future tax liabilities so long as current generations are connected to future generations by a chain of operative intergenerational transfers (either in the direction from old to young or in the direction from young to old). Applications of this result to social security and to other types of imposed intergenerational transfer schemes are also noted. In the presence of imperfect private capital markets, government debt issue will increase net wealth if the government is more efficient, at the margin, than the private market in carrying out the loan process. Similarly, if the government has monopoly power in the production of bond "liquidity services," then public debt issue will raise net wealth. Finally, the existence of uncertainty with respect to individual future tax liabilities implies that public debt issue may increase the overall risk contained in household balance sheets and thereby effectively reduce household wealth.

The assumption that government bonds are perceived as net wealth by the private sector plays an important role in theoretical analyses of monetary and fiscal effects. This assumption appears, explicitly or implicitly, in demonstrating real effects of a shift in the stock of public debt

I have benefited from comments on earlier drafts by Gary Becker, Benjamin Eden, Milton Friedman, Merton Miller, José Scheinkman, Jeremy Siegel, and Charles Upton. The National Science Foundation has supported this research. 
(see, e.g., Modigliani 1961, sec. IV; Mundell 1971; and Tobin 1971, chap. 5), and in establishing nonneutrality of changes in the stock of money (Metzler 1951, sec. VI). More generally, the assumption that government debt issue leads, at least in part, to an increase in the typical household's conception of its net wealth is crucial for demonstrating a positive effect on aggregate demand of "expansionary" fiscal policy, which is defined here as a substitution of debt for tax finance for a given level of government expenditure (see, e.g., Patinkin 1964, sec. XII.4; and Blinder and Solow 1973, pp. 324-25). The basic type of argument in a fullemployment model is, following Modigliani (1961), that an increase in government debt implies an increase in perceived household wealth; hence, an increase in desired consumption (a component of aggregate demand) relative to saving; hence, an increase in interest rates; and, finally, a decline in the fraction of output which goes to capital accumulation. However, this line of reasoning hinges on the assumption that the increase in government debt leads to an increase in perceived household wealth. In a non-full employment context it remains true that the effect of public debt issue on aggregate demand (and, hence, on output and employment) hinges on the assumed increase in perceived household wealth.

It has been recognized for some time that the future taxes needed to finance government interest payments would imply an offset to the direct positive wealth effect. For example, in a paper originally published in 1952, Tobin (1971, p. 91) notes: "How is it possible that society merely by the device of incurring a debt to itself can deceive itself into believing that it is wealthier? Do not the additional taxes which are necessary to carry the interest charges reduce the value of other components of private wealth?" Bailey (1962, pp. 75-77) has gone somewhat further by arguing: "It is possible that households regard deficit financing as equivalent to taxation. The issue of a bond by the government to finance expenditures involves a liability for future interest payments and possible ultimate repayment of principal, and thus implies future taxes that would not be necessary if the expenditures were financed by current taxation. ... If future tax liabilities implicit in deficit financing are accurately foreseen, the level at which total tax receipts are set is immaterial; the behavior of the community will be exactly the same as if the budget were continuously balanced."

There seem to be two major lines of argument that have been offered to defend the position that the offset of the future tax liabilities will be only partial. ${ }^{1}$ One type of argument, based on finite lives, supposes that

${ }^{1}$ Of course, most analyses of government debt effects do not offer a specific defense for this position. For example, Blinder and Solow (1973, p. 325, n. 8) say: "This [analysis] includes government bonds as a net asset to the public. We are well aware of, but not persuaded by, the arguments which hold that such bonds are not seen as net worth by individuals because of the implied future tax liability." 
the relevant horizon for the future taxes (which might correspond to the remaining average lifetimes of the current taxpayers) will be shorter than that for the interest payments. ${ }^{2}$ Accordingly, a stream of equal values for interest payments and taxes will have a net positive present value. This argument has been used explicitly by Thompson (1967, p. 1200). The second type of argument, usually based on imperfect private capital markets, supposes that the relevant discount rate for tax liabilities will be higher than that for the interest payments. Hence, even with an infinite horizon for tax liabilities, a stream of equal values for interest payments and taxes will have a net positive present value. This argument has been used by Mundell (1971). ${ }^{3}$

The first part of this paper deals with the effect of government bond issue on the calculus of individual wealth in an overlapping-generations economy with physical capital where individuals have finite lives. No elements of "capital market imperfections" are introduced into this model. The key result here is that, so long as there is an operative intergenerational transfer (in the sense of an interior solution for the amount of bequest or gift across generations), there will be no net-wealth effect and, hence, no effect on aggregate demand or on interest rates of a marginal change in government debt. This result does not hinge on current generations' weighing the consumption or utility of future generations in any sense on an equal basis with own consumption, nor does it depend on current generations' placing any direct weight at all on the consumption or utility of any future generation other than the immediate descendant. Current generations act effectively as though they were infinite-lived when they are connected to future generations by a chain of operative intergenerational transfers.

The analysis then shows that social security payments are analogous to changes in government debt. Marginal changes in this type (or other types) of imposed intergenerational transfers have no real effects when current and future generations are already connected by a chain of operative discretionary transfers. The effects of inheritance taxes and of "transaction costs" for government bond issue and tax collections are also considered. It is shown that inheritance taxes do not affect the basic results, but that the presence of government transaction costs implies that the net-wealth effect of government bonds would actually be negative.

The second part of the paper deals with the existence of imperfect private capital markets. It is shown that, to the extent that public debt

2 This type of argument applies to head taxes or to taxes based on wage income, but not to taxes which are based on the value of nonhuman assets. This distinction has been made by Mundell (1971, pp. 9, 10).

${ }^{3}$ A different line of argument that leads to a similar conclusion is that the government acts like a monopolist in the provision of the liquidity services yielded by its liabilities. I discuss this argument in part III, below. 
issue entails a loan from low-discount-rate to high-discount-rate individuals, a positive net-wealth effect results if the government is more efficient than the private market in carrying out this sort of loan. If the government is more efficient only over a certain range, and if the public choice process determines the amount of government debt issue in accord with efficiency criteria, it is again true at the margin that the net-wealth effect of government bond issue is nil.

The third part of the paper discusses government debt as a bearer of nonpecuniary "liquidity services." It is shown that if the government acts like a competitive producer of these services, as would be dictated by a public choice process which reflects efficiency criteria, then the netwealth effect of government bond issue would be zero on this count. More generally, the net-wealth effect would be positive if the government acts like a monopolist and would be negative if the government is an overproducer of liquidity services.

The last part of the paper deals with the risk characteristics of government debt and of the tax liabilities associated with the interest payments on this debt. It is argued that if relative tax liabilities are known, a change in government debt will not alter the overall risk contained in household balance sheets. When relative tax liabilities are uncertain, the effect of government debt issue on the overall risk may be positive or negative, depending on the nature of the tax system and on the transaction costs associated with private insurance arrangements.

\section{The Effect of Finite Lives-a Model with Overlapping Gener- ation}

\section{A. Setup of the Model}

I use here a version of the Samuelson (1958)-Diamond (1965) overlapping-generations model with physical capital. Each individual lives two periods, which will be distinguished by the superscripts $y$ (young) and $o$ (old). Generations are numbered consecutively beginning with the generation which is currently old (subscript 1 ); followed by its descendant, which is currently young (subscript 2); followed by its descendant; and so on. I assume here that there are the same number of people, $N$, in each generation, and that all individuals are identical in terms of tastes and productivity. I also abstract from any technological change over time. The members of each generation work (a fixed amount of time set equal to one unit) only while young and receive an amount of wage income $w$. Expectations on $w$ for future periods (i.e., for future generations) are assumed to be static at the current value. Asset holdings $(A)$ take the form of equity capital $(K)$. Subsequently, government bonds are introduced as an additional form in which assets can be held. The rate of return on assets 
is denoted by $r$ and is assumed to be paid out once per period. Expectations on $r$ for future periods are assumed to be static at the current value. A member of the $i$ th generation holds the amount of assets $A_{i}^{y}$ while young and the amount $A_{i}^{o}$ while old. The asset holding while old constitutes the provision of a bequest, which is assumed to go to the immediate descendant, a member of generation $i+1$. Since the focus of the analysis concerns shifts in tax liabilities and government debt for a given level of government expenditure, it is assumed for convenience that the government neither demands commodities nor provides public services. In this section, it is also assumed that the amounts of government debt and taxes are zero. Using the letter $c$ to denote consumption, and assuming that consumption and receipt of interest income both occur at the start of the period, the budget equation for a member of generation 1, who is currently old, is

$$
A_{1}^{y}+A_{0}^{o}=c_{1}^{o}+(1-r) A_{1}^{o} .
$$

The total resources available are the assets held while young, $A_{1}^{y}$, plus the bequest from the previous generation, $A_{0}^{o}$. The total expenditure is consumption while old, $c_{1}^{o}$, plus the bequest provision, $A_{1}^{o}$, which goes to a member of generation 2, less interest earnings at rate $r$ on this asset holding.

The budget equation for members of generation 2 (and, more generally, for members of any generation $i \geq 2$ ) is, assuming that wage payments occur at the start of the young period,

$$
w=c_{2}^{y}+(1-r) A_{2}^{y},
$$

and, for the old period,

$$
A_{2}^{y}+A_{2}^{o}=c_{2}^{o}+(1-r) A_{2}^{o} .
$$

A portion of the lifetime resources of a member of generation $i$ goes to a bequest provision, $A_{1}^{o}$, which I assume is motivated by a concern for a member of generation $i+1$. This concern could be modeled by introducing either the (anticipated) consumption levels or attainable utility of a member of generation $i+1$ into the utility function for a member of the $i$ th generation. For the purpose of the present analysis, the crucial condition is that this utility depend on the endowment of a member of generation $i+1$ rather than, per se, on the gross bequest, $A_{1}^{o}$. (The distinction between the gross bequest and the net bequest, which determines the endowment of $i+1$, will be discussed below.) So long as a member of generation $i$ can transfer resources to a member of generation $i+1$ only through the transfer of unrestricted purchasing power (which rules out the "merit good" case discussed in n. 8 below), the two types of models of interdependent preferences-concern with consumption levels and concern with attainable utility-will be equivalent in the sense of 
indirectly implying a concern for the endowment of a member of generation $i+1$.

For present purposes, it is convenient to assume that the utility of a member of generation $i$ depends solely on own two-period consumption, $c_{i}^{y}$ and $c_{i}^{o}$, and on the attainable utility of his immediate descendant, $U_{i+1}^{*}$. The asterisk denotes the maximum value of utility, conditional on given values of endowment and prices. Hence, the utility function for a member of the $i$ th generation has the form, ${ }^{4}$

$$
U_{i}=U_{i}\left(c_{i}^{y}, c_{i}^{o}, U_{i+1}^{*}\right) .
$$

Subsequently, I consider the implications of entering the attainable utility of a member of the previous generation, $U_{i-1}^{*}$, as an additional argument of the $U_{i}$ function.

Each member of generation 1 determines his allocation of resources to maximize $U_{1}$, subject to equations $(1)-(4)$ and to the inequality conditions, $\left(c_{i}^{y}, c_{i}^{o}, A_{i}^{o}\right) \geq 0$ for all $i$. The key restriction here is that the bequest to the member of the next generation cannot be negative. ${ }^{5}$ The choice of bequest, subject to this restriction, takes into account the effect of $A_{1}^{o}$ on generation 2's resources, the impact of $U_{2}^{*}$ on $U_{1}$, and the chain dependence of $U_{2}$ on $U_{3}^{*}$, of $U_{3}$ on $U_{4}^{*}$, etc. The solution to this problem will take the general form

$$
\begin{aligned}
& c_{1}^{o}=c_{1}^{o}\left(A_{1}^{y}+A_{0}^{o}, w, r\right), \\
& A_{1}^{o}=\frac{1}{1-r}\left(A_{1}^{y}+A_{0}^{o}-c_{1}^{o}\right)=A_{1}^{o}\left(A_{1}^{y}+A_{0}^{o}, w, r\right) .
\end{aligned}
$$

Similarly, for members of generation 2 (and, more generally, for members of any generation $i \geq 2$ ), the solution would take the form,

$$
\begin{aligned}
c_{2}^{y} & =c_{2}^{y}\left(A_{1}^{o}, w, r\right), \\
A_{2}^{y} & =\frac{1}{1-r}\left(w-c_{2}^{y}\right)=A_{2}^{y}\left(A_{1}^{o}, w, r\right), \\
c_{2}^{o} & =c_{2}^{o}\left(A_{2}^{y}+A_{1}^{o}, w, r\right), \\
A_{2}^{o} & =\frac{1}{1-r}\left(A_{2}^{y}+A_{1}^{o}-c_{2}^{o}\right)=A_{2}^{o}\left(A_{2}^{y}+A_{1}^{o}, w, r\right) .
\end{aligned}
$$

${ }^{4} \mathrm{~A}$ member of generation $i$ is assumed to be concerned with own consumption and with the attainable indifference surface of his descendant. Further, it is supposed that a member of generation $i$ can attach a metric to generation $i+1$ 's indifference surface which makes it comparable to $c_{i}^{y}$ and $c_{i}^{c}$ in terms of generating $U_{i}$ in the form of eq. (4). The nature of this sort of utility function is discussed in the general context of interdependent preferences in Becker (1974, sec. 3.A).

${ }^{5}$ I have not imposed the condition, $A_{i}^{y} \geq 0$, so that young individuals are allowed to issue interest-bearing debt on themselves. If issued, these debts are assumed to be perfect substitutes for equity capital. These debts correspond to the consumption loans which have been discussed by Samuelson (1958). 
The model can be closed, as in Diamond (1965, pp. 1130-35), by specifying a constant-returns-to-scale production function that depends on the amounts of capital and labor input, and by equating the marginal products of capital and labor to $r$ and $w$, respectively. The value of $r$ for the current period would then be determined in order to equate the supply of assets to the demand-that is,

$$
K(r, w)=A_{1}^{o}+A_{2}^{y},
$$

where $K(r, w)$ is such as to equate the marginal product of capital to $r$. The current demand for assets, $A_{1}^{o}+A_{2}^{y}$, depends, from equations (5) and (6), on $r, w$, and the previous period's value of $K$, which is equal to $A_{1}^{y}+A_{0}^{o}$. Since the number of people in each generation is assumed to equal a fixed number $N$, it is not necessary to enter this number explicitly into the aggregate asset demand in equation (7). Similarly, $N$ is omitted from the aggregate formulations below. Since $N$ is constant and technical change is not considered, the current and previous periods' values of $K$ would be equal in a steady state.

With the marginal product of labor equated to $w$ and with constant returns to scale, output is given by

$$
y=r K+w .
$$

Equations (2), (3), (7), and (8) imply a commodity market clearing condition,

$$
c_{1}^{o}+c_{2}^{y}+\Delta K=y,
$$

where $\Delta K$ denotes the change in capital stock from the previous to the current period. The value of $\Delta K$ would be zero in a steady state, but the present analysis is not restricted to steady-state situations.

\section{B. Government Debt}

Suppose now that the government issues an amount of debt, $B$, which can be thought of as taking the form of one-period, real-valued bonds. These bonds pay the specified amount of real interest, $r B$, in the current period and the specified real principal, $B$, in the next period. ${ }^{6}$ It is supposed that asset holders regard equity and government bonds as perfect substitutes. It can be assumed, for simplicity, that the government bond issue takes the form of a helicopter drop to currently old (generation 1) households. Equivalently, it could be assumed that the bonds were sold on a competitive capital market, with the proceeds from this sale used to effect a lump-sum transfer payment to generation 1 households.

6 The amount of bond issue would be limited by the government's collateral, in the sense of its taxing capacity to finance the interest and principal payments (see n. 12 below). 
Allowing some portion of the proceeds to go to generation 2 households would not alter any of the basic conclusions.

The future interest payments on the government debt must be financed in some manner. Further, the principal may eventually be paid offthat is, the government may not reissue the bonds when they come due in the next period. I assume, provisionally, that the current period's interest payments are financed by a lump-sum tax levy on generation 2 households (while young), and that the principal is paid off at the beginning of the next period by an additional lump-sum tax levy on generation 2 households (while old). In this setup there is no direct effect of the government debt issue and its financing on generation 3 and later generations. I examine, subsequently, the implications of imposing some part of the taxes on generations of the more distant future.

The generation 1 budget constraint is now

$$
A_{1}^{y}+A_{0}^{o}+B=c_{1}^{o}+(1-r) A_{1}^{o},
$$

where $B$ represents the lump-sum transfer payment, which is assumed to occur at the beginning of the period. For generation 2, the current budget constraint is now

$$
w=c_{2}^{y}+(1-r) A_{2}^{y}+r B,
$$

where $r B$ represents the tax levy for the government interest payments. The next period's budget constraint for generation 2 is now

$$
A_{2}^{y}+A_{1}^{o}=c_{2}^{o}+(1-r) A_{2}^{o}+B,
$$

where $B$ represents the tax levy for repayment of principal. The two constraints on generation 2 can be combined into a single two-period budget equation,

$$
w+(1-r) A_{1}^{o}-B=c_{2}^{y}+(1-r) c_{2}^{o}+(1-r)^{2} A_{2}^{o} .
$$

The form of equation (12) implies that the utility attainable by a member of generation 2 can be written in the indirect form,

$$
U_{2}^{*}=f_{2}^{*}\left[(1-r) A_{1}^{o}-B, w, r\right],
$$

that is, the "net bequest," $(1-r) A_{1}^{o}-B$, determines the "endowment" for members of generation 2.

From equation (10), it is also clear that $c_{1}^{o}$ varies inversely with $(1-r) A_{1}^{o}-B$ for a given value of $A_{1}^{y}+A_{0}^{o}$. Hence, given the predetermined value of $c_{1}^{y}$, and using equations (4), (10), and (13), $U_{1}$ can be written in the form,

$$
U_{1}=U_{1}\left(c_{1}^{y}, c_{1}^{o}, U_{2}^{*}\right)=f_{1}\left[(1-r) A_{1}^{o}-B ; c_{1}^{y}, A_{1}^{y}+A_{0}^{o}, w, r\right] .
$$

For given values of $c_{1}^{y}, A_{1}^{y}+A_{0}^{o}$, w, and $r$, the choice problem for members of generation 1 amounts to the optimal selection of the net bequest, 
$(1-r) A_{1}^{o}-B$, subject to the constraint that the gross bequest, $A_{1}^{o}$, be nonnegative. In particular, if the solution to this problem is associated with a value of $A_{1}^{o}$ in the interior-that is, if the constraint, $A_{1}^{o} \geq 0$, is not binding - any marginal change in $B$ would be met solely by a change in $A_{1}^{o}$ that maintains the value of the net bequest, $(1-r) A_{1}^{o}-B$. This response in $A_{1}^{o}$ will keep unchanged the values of $c_{1}^{o}, c_{2}^{y}, c_{2}^{o}$, and $A_{2}^{o}$. Hence, the utility levels attained by members of generations 1, 2, etc., will be unaffected by the shift in $B$.

In terms of the effect on $r$, the current asset market clearing condition of equation (7) would now be modified to

$$
K(r, w)+B=A_{1}^{o}+A_{2}^{y} .
$$

The increase in $B$ implies a one-to-one increase in the asset supply on the left-hand side of equation (14). However, $A_{1}^{o}$ rises by $1 /(1-r)$ times the change in $B$ in order to maintain the size of the net bequest, $(1-r) A_{1}^{o}-B$. Further, with $c_{2}^{y}$ fixed, the increase in $r B$ (taxes) in equation (11) implies that $A_{2}^{y}$ falls by $r /(1-r)$ times the change in $B$. On net, total asset demand on the right-hand side of equation (14) rises one-to-one with $B$, so that no change in $r$ is required to clear the asset market. Equivalently, the commodity market clearing condition, as expressed in equation (9), continues to hold at the initial value of $r$ because the bond issue has no impact on aggregate demand.

Essentially, a positive value of $B$, financed by a tax levy on the next generation, enables a member of the old generation to "go out" insolvent by leaving a debt for his descendant. However, if, prior to the government bond issue, a member of the old generation had already selected a positive bequest, it is clear that this individual already had the option of shifting resources from his descendant to himself, but he had determined that such shifting, at the margin, was nonoptimal. Since the change in $B$ does not alter the relevant opportunity set in this sense, it follows that - through the appropriate adjustment of the bequest - the values of current and future consumption and attained utility will be unaffected. On the other hand, if a member of generation 1 were initially at a corner where $A_{1}^{o}=0$-in particular, if $A_{1}^{o}<0$ would have been chosen had it been permissible-then an increase in $B$ creates a relevant new opportunity. In this situation a generation 1 household would react by increasing $c_{1}^{o}$ along with $B$, as long as the corner solution for $A_{1}^{o}$ still applied. The upward shift in $B$ would then correspond to an excess of earning-asset supply over demand (even after taking account of a shift in $A_{2}^{y}$ ), which would tend to raise the value of $r$. This increase in $r$ would induce a drop in capital formation, which constitutes the real effect of government debt issue which has been described by Modigliani (1961). However, the main point is that the existence of this government debt effect hinges on a non- 
operative bequest motive-that is, on households being at the corner where the amount of bequest is zero. ${ }^{7}$

It should be stressed that the crucial consideration for the above result is an operative intergenerational transfer, rather than an operative bequest motive per se. For example, the transfer could take the form of parental expenditure on children's education, etc., during the overlapping tenure of parent and child. ${ }^{8}$ Further, the transfer could be occurring in the direction opposite to that specified above. In particular, $U_{1}^{*}$ could be entered as an argument of the $U_{2}$ function, and the possibility of gifts from the young to the old generation could be introduced. In that case the same conclusions on the effect of a change in the government debt would be reached if a "gift motive" were operative. ${ }^{9}$ The mechanism through which changes in $B$ were offset would then be an alteration in the amount of gifts from young to old, rather than an alteration of the amount of bequests from old to young.

The results will now be extended to a situation where the taxes which finance the government debt affect some generations which are not currently alive. The extension will be made explicitly only to generation 3 , since the extension to generations further advanced in the future is straightforward.

Suppose now that the current period's interest payments are financed by a lump-sum tax levy on (young) generation 2, the next period's interest payments (on the reissued bonds) are financed by a lump-sum tax levy on (young) generation 3, and the principal is paid off by a lump-sum tax levy on (old) generation $3 .^{10}$ The generalization of the earlier results to this situation can be demonstrated by working backward from generation 3. By analogy to equation (13), the attainable utility of generation 3 can

${ }^{7}$ When households are not identical, the aggregate effect of government debt issue will depend on the fraction of households at a corner. As long as some households are in this situation, a shift in $B$ will have some upward effect on $r$ in this model. However, this effect would be "small" if the fraction of households at a corner were small. The role of a bequest motive in eliminating the perceived net-wealth effect of government debt has also been discussed by Miller and Upton (1974, pp. 176-79).

${ }^{8}$ The previous results on the effect of $B$ might not hold if parents were concerned with specific consumption components of their children ("merit goods"), rather than with their children's attainable utility. Formally, $U_{i}$ in eq. (4) could depend on (components of) $c_{i+1}^{y}$ or $c_{i+1}^{o}$, rather than on $U_{i+1}^{*}$. If generation $i$ can tie its aid to generation $i+1$ to a specific type of expenditure (as could be the case for education), the previous results would not hold if this tied aid were an effective constraint-in the sense of forcing the next generation to "purchase" more of the item than it otherwise would-and if the parents were not making any other transfers which were equivalent to the transfer of general purchasing power. Becker (1974, sec. 3.C) presents a detailed discussion of the merit goods case in an analogous context.

${ }^{9}$ A model which allows for a reciprocal dependence between $U_{i}$ and $U_{i+1}$ is formally similar to the model discussed by Becker (1974, sec. 3.A) in the context of transfer payments among members of a family.

${ }^{10}$ I do not deal here with the possibility of net government debt issue during the old-age tenure of generation 2. No new considerations would arise here (see however, n. 12 below). 
be written in the indirect form,

$$
U_{3}^{*}=f_{3}^{*}\left[(1-r) A_{2}^{o}-B, w, r\right],
$$

where $(1-r) A_{2}^{o}-B$ now determines the endowment for members of generation 3. Since generation 2 no longer pays off the government debt principal, its budget equation is modified from the form of equation (12) to

$$
w+(1-r) A_{1}^{o}-B=c_{2}^{y}+(1-r) c_{2}^{o}+(1-r)\left[(1-r) A_{2}^{o}-B\right] \text {. }
$$

For given values of $w, r$, and the net bequest from generation 1, $(1-r) A_{1}^{o}-B$, generation 2 would select an optimal value of the net bequest to generation $3,(1-r) A_{2}^{o}-B$. This net bequest would be invariant with $B$ as long as the solution for $A_{2}^{o}$ were interior. Assuming that this solution is interior, the attainable utility of generation 2 can be written in the indirect form,

$$
U_{2}^{*}=f_{2}^{*}\left[(1-r) A_{1}^{o}-B, w, r\right],
$$

which coincides in form with equation (13). The situation has therefore been reduced to the previous case in which marginal changes in $B$ led solely to changes in $A_{1}^{o}$ which kept $(1-r) A_{1}^{o}-B$ constant without affecting any values of consumption or attained utility.

The three-generation results generalize to the case in which taxes are levied on $m$ generations, with the $m$ th generation paying off the principal. By starting with generation $m$ and progressing backward, it can be shown for all $2 \leq i \leq m-1$ that, if $A_{i}^{o}$ is interior, $U_{i}^{*}$ can be written in an indirect form as a function of $(1-r) A_{i-1}^{o}-B$. As long as all inheritance choices are interior ${ }^{11}$ (as anticipated by current generations), shifts in $B$ imply fully compensating shifts in bequests, so as to leave unchanged all values of consumption and attained utility. ${ }^{12}$

${ }^{11}$ Intuitively, if this condition is violated for some generations, the impact of these violations on current behavior should be less important the further in the future the violating generations. I make no claim to having proved this conjecture.

12 This line of proof does not apply as $m \rightarrow \infty$. The main issue seems to be whether the assumption that the principal is eventually paid off is crucial. If the amount of outstanding government debt were constant, the impact of the principal on current decisions would become negligible for large $m$ as long as $r>0$. However, a difficulty arises here when $B$ is allowed to grow over time. Suppose that the growth of $B$ were limited to the growth of the government's collateral in the sense of its taxing capacity, which depends in turn on the growth of real income. Suppose that the growth rate of real income is equal to $n$, which can be viewed as the combined effects of population growth and technical progress, which are now allowed to be positive. In that case the present value of the principal would have to become negligible as $m \rightarrow \infty$ if $n<r$. The situation in which $n>r$ applies is inefficient in that it is associated with a capital stock in excess of the golden rule level (see, e.g., Diamond 1965, p. 1129). It is possible in Diamond's model (p. 1135) that the competitive equilibrium can be in this inefficient region. However, this situation is not possible in growth models where individuals are infinite lived and utility is discounted (see, e.g., Koopmans 1965). As long as intergenerational transfers are operative, the overlapping-generations model would seem to be equivalent to the infinite-life model in this respect - that is, the possibility of inefficiency in Diamond's model seems to hinge on finite lives with inoperative intergenerational transfers. Hence, when these transfers are operative, $n<r$ would be guaranteed, and the possibility of perpetual government finance by new debt issue could then be ruled out. 
The results in this section have demonstrated that changes in government debt would not induce any alteration in consumption plans even in a model where (1) the present generations have finite lives, (2) the present generations may, in some sense, give lesser weight to the consumption or utility of future generations than they give to own consumption, and (3) the present generation may give no direct weight at all to the consumption or utility of generations beyond their immediate descendants (who are also finite-lived).

A sufficient condition for changes in government debt to have no impact on consumption plans and, hence, no effect on aggregate demand and interest rates is that the solution for the current generations' inheritances be interior, and that the solutions for future generations' inheritances (as perceived by current generations) also be interior. More generally, the result will hold as long as current generations are connected to all future generations by a chain of operative intergenerational transfers, either in the direction from old to young or in the direction from young to old.

The derivation of conditions under which the solution for intergenerational transfer would be interior appears to be a difficult problem and would seem to require some specialization of the form of the utility functions in order to make any headway. However, it seems clear that bequests are more likely to be positive the smaller the growth rate of $w$ (assuming that $w$ is now viewed as variable across generations), the higher the interest rate, the higher the relative weight of $U_{i+1}^{*}$ in the $U_{i}$ function, and the larger the value of $B .{ }^{13}$ The reverse conditions favor a gift from young to old. ${ }^{14}$

\section{Social Security Payments and Other Imposed Intergenerational Transfers}

The above results on government debt also apply to social security payments. ${ }^{15}$ Suppose that a scheme is instituted which immediately begins payments to the current old generation (generation 1) of amount $S$, financed by a lump-sum tax levy of amount $S$ on the current young

${ }^{13}$ In a more general context $B$ should be viewed as outstanding public debt less the value of physical capital held by the government.

${ }^{14}$ There is an alternative argument, which Gary Becker refers to as the "enforcement theory of giving," which suggests that bequest motives would typically be operative. Suppose that, instead of receiving utility from the perceived utility of his child, a parent is concerned with own consumption and with the amount of attention, etc., shown by his child during their overlapping tenure. Suppose, further, that the child has some information on the size of his parents' estate and that - acting as a good optimal controllerhe regulates the amount of attention as a function of the estate size. In this situation the estate would surely be positive if parents place a high value on getting at least a small amount of attention, and if the child provides no attention when the estate is zero. However, although a positive estate could be guaranteed in this fashion, it seems that the previous conclusions about the marginal effect of $B$ on consumption plans would not hold in this model. The nature of the interactions between parents and children would have to be analyzed more fully for this case.

15 The view of social security as analogous to government debt has also been taken by Miller and Upton (1974, pp. 182-84). 
generation (generation 2). Generation 2 expects to receive a transfer of amount $S$ while old, financed by a lump-sum tax levy on (young) generation 3, etc. It is assumed here that an individual's payment received while old is independent of his own contribution to the scheme while young, and that neither the old receipt nor the young payment depends on the amount of work, income, etc. Assuming interior bequests (which would be guaranteed by a sufficiently high value of $S$ ), a change in $S$ would induce the current old generation (generation 1) to maintain its choice of $c_{1}^{o}$ and, correspondingly, to raise $A_{1}^{o}$ by $1 /(1-r)$ times the change in $S$. This increased inheritance would just offset the increased tax liability imposed on (young) generation 2. With its consumption unchanged, generation 2 would use its own higher social security receipt to raise its bequest to generation $3, A_{2}^{o}$, by $1 /(1-r)$ times the change in $S$. As in the case of changes in government debt, if the solutions for bequest are interior, the impact of a marginal change in $S$ would be solely on the size of bequests and not at all on the pattern of consumption. ${ }^{16}$ The same results would follow in the case of operative intergenerational transfers from young to old, with a marginal increase in $S$ implying a corresponding reduction in the size of gifts from young to old.

The results for social security payments would apply also to other programs which amount to imposed intergenerational transfer schemes. In particular, public support of education involves a forced transfer of resources from old to young. In the main, this sort of imposed transfer would be offset by adjustments in the opposite direction of discretionary transfers. ${ }^{17}$

\section{Inheritance Taxes}

Suppose now that inheritances (or gifts) are taxed at a proportionate rate $\tau$. In particular, the bequest from a member of generation $i, A_{i}^{o}$, yields a

${ }^{16}$ As in the case of government debt issue, the formal proof depends on the assumption that the scheme is eventually liquidated (see $n .12$ above). The consumption patterns would also not be affected by a social security scheme that involved the accumulation of a government "trust fund." Assuming that the fund were held in the form of earning assets, an increase in the fund would be equivalent to a negative government debt issue. Real effects of a social security system would arise if the payments were contingent on the work behavior of the old generation. In that case there would be allocative effects produced by the disincentive to work in later years.

${ }^{17}$ On a theoretical level, government education programs will involve real effects to the extent that (1) there is an efficiency difference between public and private production of education, (2) public expenditure on education is pressed sufficiently far so that a reduction of discretionary transfers cannot occur on a one-for-one basis, and (3) there are distributional effects involving relative educational expenditures and tax liabilities across families. As an empirical matter, Peltzman (1973) has shown that public subsidies for higher education are offset to an extent of about 75 percent by reductions in private expenditures for higher education. However, Peltzman's 75 percent figure does not coincide with the desired estimate of the effect on discretionary transfers, since other components of discretionary transfers may also be affected and (on the other side) since not all private expenditures for education constitute intergenerational transfers. 
net receipt to his descendant, a member of generation $i+1$, of size $(1-\tau) A_{i}^{o}$. Of course, the tax receipts must also go somewhere. Suppose that these receipts are transferred to members of generation $i+1$ (while old) in accordance with a rule that is independent of the size of each individual's inheritance.

Since an individual's contribution to general tax revenue will typically be valued by him at less than an equal amount of own income, it is clear that an increase in $\tau$ will tend to lower the amount of intergenerational transfers. In particular, the higher the value of $\tau$, the less likely that a bequest or gift motive will be operative. Suppose, however, that the value of $\tau$ is sufficiently low that all intergenerational transfers are operative, even if at reduced levels. In this case the previous results on the effect of a change in government debt remain valid.

Consider the situation in which the principal on the government debt is paid off by generation 2. Equation (10) continues to apply in the presence of inheritance taxes, but equation (12) must be modified to

$$
\begin{aligned}
w+(1-r)(1-\tau) A_{1}^{o}+(1-r) \tau \overline{A_{1}^{o}}-B \\
=c_{2}^{y}+(1-r) c_{2}^{o}+(1-r)^{2} A_{2}^{o},
\end{aligned}
$$

where $\tau \overline{A_{1}^{o}}$ represents the transfer to a member of (old) generation 2 corresponding to his share of the receipts from the total taxes paid on the average generation 1 bequest, $\overline{A_{1}^{o}}$. In deciding on a plan for consumption and intergenerational transfers, an individual is assumed to treat $\tau \overline{A_{1}^{o}}$ as exogenous. Consider the conjecture that, when $B$ rises, each member of generation 1 continues to respond by maintaining the value of $c_{1}^{o}$ and, hence, by maintaining the value of the net pretax bequest, $(1-r) A_{1}^{o}-B$. This response requires an increase in $A_{1}^{o}$ by $1 /(1-r)$ times the increase in $B$. Each individual's net posttax bequest would fall in this case, but this fall would be offset, at least on average, by an increase in the transfers to generation 2 which are financed from the inheritance tax receipts, $\tau \overline{A_{1}^{o}}$. In this circumstance, the individual values of $c_{2}^{y}, c_{2}^{o}$, and $A_{2}^{o}$-and, hence, the attained value of $U_{2}$-would remain fixed. Hence, by maintaining the net pretax bequest, each member of generation 1 achieves the same combination of $c_{1}^{o}$ and $U_{2}^{*}$ as before the shift in $B$. On the other hand, if an individual member of generation 1 decided to increase his net pretax bequest, while all other members held their net pretax bequests fixed, it would turn out for this individual that $U_{2}^{*}$ would increase, while $c_{1}^{o}$ would decrease. The terms on which an individual can exchange $c_{1}^{o}$ for $U_{2}^{*}$ depend on $\tau$ and $r$, and these terms have not been altered by the change in $B$. Further, when the transfer to generation 2 of size $\tau \overline{A_{1}^{o}}$ is included, there is also no change in an individual's overall wealth position. Therefore, the pattern which maintains the net pretax bequest-and thereby 
involves no shift in $c_{1}^{o}$ or $U_{2}^{*}$-must be the optimal pattern for an individual. It follows that constancy of the net pretax bequest for all members of generation 1 is the equilibrium solution. ${ }^{18}$ In this case, a marginal shift in $B$ again has no effect on consumption patterns.

The basic conclusion here is that the existence of taxes on intergenerational transfers makes less likely an interior solution for these transfers, but if these transfers are operative, even if at reduced levels, the marginal effect of $B$ on consumption plans-and, hence, on $r$-remains nil.

\section{E. Bond Issue and Tax-Collection Costs}

Suppose now that the issue of government debt and the collection of taxes to finance this debt involve transaction costs. In particular, in the case where the principal is paid off by generation 2, suppose that a net issue of $B$ to generation 1 is now associated with a tax levy of $(1+\gamma) r B$ on (young) generation 2 and a levy of $(1+\gamma) B$ on (old) generation 2 . That is, $\gamma$ amounts to a proportional transaction cost associated with government debt issue and tax collection. ${ }^{19}$ For simplicity, suppose now that the inheritance tax rate is zero. Equation (10) again remains valid, but equation (12) is now modified to

$$
w+(1-r) A_{1}^{o}-(1+\gamma) B=c_{2}^{y}+(1-r) c_{2}^{o}+(1-r)^{2} A_{2}^{o} .
$$

Consider, again, the conjecture that, when $B$ rises, $c_{1}^{o}$ and, hence, $(1-r) A_{1}^{o}-B$ remain fixed. From equation (15), $\gamma>0$ implies a negative-wealth effect on generation 2, so that $U_{2}^{*}$ would fall. Since this effect would be anticipated by generation 1, it can be supposed in the normal case that $A_{1}^{o}$ would actually rise by somewhat more than $1 /(1-r)$ times $B$, so that $c_{1}^{o}$ would fall. In general, $\gamma>0$ implies that an increase in $B$ amounts to an overall negative-wealth effect, which would

18 The equilibrium satisfies two properties: (1) each individual chooses his bequest optimally, subject to a given choice of bequests by all other individuals; and (2) all individuals choose the same value for their bequests. It can also be shown that the solution that maintains the net pretax bequest for all individuals is the unique equilibrium. Finally, it can be noted that the solution involves the assumption that each individual perceives the shift in the transfer term, $\tau \overline{A_{1}^{o}}$, associated with the average response of bequests to the change in $B$. A!ternatively, if individuals treated $\tau \overline{A_{1}^{0}}$ as fixed, they would view an increase in $B$ as, effectively, a negative change in wealth. The typical response would be a reduction in $c_{1}^{o}$, which would be associated with an increase in $A_{1}^{o}$ by more than $1 /(1-r)$ times the change in $B$. In the aggregate, there would be an increase in desired saving, $A_{2}^{o}+A_{1}^{y}$, which would lead to a reduction in $r$ and to an increase in capital formation. In particular, if the shift in transfers associated with inheritance tax revenues, $\tau \overline{A_{1}^{o}}$, is not perceived, the effects would be opposite to the standard case in which perceived net wealth rises with $B$.

19 If the initial debt issue is associated with a decrease in other taxes, rather than an increase in transfers, there could be an offsetting reduction in transaction costs. The parameter $\gamma$, which is assumed to be positive, must be interpreted in this net sense. 
typically involve reductions in both $c_{1}^{o}$ and $U_{2}^{*}$. This effect can be seen by combining equations (10) and (15) into the single two-generation budget equation,

$$
A_{1}^{y}+A_{0}^{o}-\gamma B+w=c_{1}^{o}+c_{2}^{y}+(1-r) c_{2}^{o}+(1-r)^{2} A_{2}^{o} .
$$

The decline in total resources on the left-hand side of equation (16) produced by an increase in $B$ would typically be reflected in declines in all terms on the right-hand side $-c_{1}^{o}, c_{2}^{y}, c_{2}^{o}$, and $A_{2}^{o}$.

In this circumstance the effect on $r$ of a shift in $B$ would be unclear. The commodity market clearing condition of equation (9) would now be modified to include the resources devoted to bond and tax transactions. The revised market clearing condition would be

$$
c_{1}^{o}+c_{2}^{y}+\Delta K+\gamma r B=y .
$$

The effect of $B$ on current $r$ will depend on whether, for a given value of $r$, the sum, $c_{1}^{o}+c_{2}^{y}$, falls by more or less than the increase in $\gamma r B$. This relationship seems to be ambiguous. ${ }^{20}$

\section{Imperfect Capital Markets}

This part of the paper analyzes the implications of divergences among individual discount rates. This source of a net-wealth effect for government bonds has been stressed by Mundell (1971), who argues that, because of high discount rates for some individuals, the taxes which finance the government debt will not be fully capitalized-hence, an issue of government bonds will involve a net-wealth effect. To analyze this effect, it is necessary to construct a somewhat different model. Suppose that there are now two types of individuals--those who have a low discount rate, $r_{l}$, and those who have a high discount rate, $r_{h}$. It can be supposed that the highdiscount-rate individuals have relatively "bad collateral," so that loans to these individuals involve high transaction costs, which are reflected in high (net-of-default-risk) borrowing rates. ${ }^{21}$ In particular, suppose that the two discount rates are related according to

$$
r_{h}=(1+\lambda) r_{l}
$$

where $\lambda>0$ represents the proportional transaction costs involved in the loan process. ${ }^{22} \mathrm{I}$ suppose in this part of the paper that both types of

${ }^{20}$ From eq. (16), the negative wealth effect is $\gamma B$, which is the present value of the flow, $\gamma r B$. The sum, $c_{1}^{o}+c_{2}^{y}$, will fall by as much as $\gamma r B$ if the total "propensity to consume" associated with the negative "income" flow, $\gamma r B$, is equal to one.

${ }^{21}$ In this respect see Barro (1974).

22 I am assuming that the $r_{h}$ individuals are actually borrowing, so that $r_{h}$ represents both their borrowing rate and their marginal discount rate. Alternatively, $r_{h}$ could be viewed as a marginal discount rate which could be somewhere between the borrowing and lending rates, as in Hirshleifer (1958). 
individuals are infinite-lived, since the effect of finite lives has already been examined above.

It is convenient to suppose that government debt now takes the form of a perpetuity that carries a real interest payment of $i$ per year. Suppose that the government issues an additional bond of this type. This bond would be purchased by a low-discount-rate individual and would be evaluated as $B=i / r_{l} \cdot{ }^{23}$ Suppose then that the government uses the lump-sum proceeds from this sale, $B$, to effect a lump-sum transfer (or lump-sum tax reduction) to individuals, and suppose that a fraction $\alpha$ of this transfer goes to $r_{l}$ discount rate individuals and a fraction $(1-\alpha)$ to $r_{h}$ discount rate individuals. Finally, the taxes for financing the government interest payments are $(1+\gamma) i$, where $\gamma$ represents, as in section $I E$, the proportional transaction costs associated with government bond sale and tax collection. Suppose that these taxes are distributed across discount rates in the same manner as the lump-sum proceeds ${ }^{24}$ - that is, a fraction $\alpha$ to $r_{l}$ individuals and a fraction $(1-\alpha)$ to $r_{h}$ individuals.

Consider, in turn, the wealth effects for the $r_{l}$ and $r_{h}$ groups. The bond sale itself involves no wealth effect for the $r_{l}$ group. The lump-sum transfer to $r_{l}$ individuals is $\alpha B=\alpha i / r_{l}$, while the present value of the $r_{l}$ share of tax liabilities, discounted at rate $r_{l}$, is $(1+\gamma) \alpha i / r_{l}$. Clearly, if $\gamma>0$, the net-wealth effect for $r_{l}$ individuals is negative, as it was in the case discussed in section $I E$, where all discount rates were equal.

For the $r_{h}$ group, the lump-sum proceeds are $(1-\alpha) B=(1-\alpha) i / r_{l}$, while the present value of the tax liability, discounted at rate $r_{h}$, is $(1+\gamma)(1-\alpha) i / r_{h}$. Using $r_{h}=(1+\lambda) r_{l}$, the net-wealth effect here can be expressed as

$$
\frac{(1-\alpha) i}{r_{l}}\left(1-\frac{1+\gamma}{1+\lambda}\right)=\frac{(1-\alpha) i}{r_{l}(1+\lambda)}(\lambda-\gamma),
$$

which is positive if $\lambda>\gamma$. That is, the net-wealth effect for the $r_{h}$ group is positive if $\gamma$, which measures the government transaction costs for bond issue and tax collection, is smaller than $\lambda$, which measures the private transaction costs implicit in the existing pattern of (net-of-default-risk) discount rates. To the extent, $1-\alpha$, that the transfer payment and tax liability involve the $r_{h}$ group, the government bond issue amounts to effecting a loan from the low-discount-rate to the high-discount-rate individuals. On the other hand, this sort of transfer could already have

23 This analysis abstracts from any "liquidity yield" of bonds (see part III, below).

24 If the fractions for transfer and tax liability vary, then the wealth effects on the two discount-rate groups are likely to be in opposite directions. The net effect on current consumption demand would depend, in part, on relative propensities to consume, which are not obvious. In any event, this case would amount to the effect of income distribution on consumption demand, rather than the effect of government bond issue per se on net wealth and consumption demand. 
been accomplished privately, except that the transaction costs, as measured by $\lambda$, made this transfer marginally unprofitable. Hence, the government-induced transfer implied by its bond issue can raise net wealth only if the government is more efficient than the private capital market in carrying out this sort of lending and borrowing operation.

Some additional observations can be made concerning this result. First, if the government is really more efficient than the private market in the lending process (presumably because the benefits of economies of scale [in information?] and the ability to coerce outweigh the problems of government incentive and control), it may be able to exploit this efficiency better by a direct-loan program, rather than by the sort of bond issue described above. In my simple model, a fraction $\alpha$ of transfers and tax liabilities involved the $r_{l}$ group, and this process entailed a dead-weight loss to the extent that $\gamma>0$. A program which limited the loan recipients to high-discount-rate individuals would be more efficient in this respect. However, the information requirements for this sort of program may be much greater than those for a program which does not attempt to discriminate--in the transfer and tax liability aspects-among discount rates. The crucial point which can make the bond issue work as a loan program is that the purchasers of the bonds automatically discriminate among themselves as to their discount rates.

Second, the government may be more efficient than the private market only over a certain range of $B$. In particular, there may be a sufficiently large value of $B$ such that, at the margin, the net-wealth effect of government debt is zero. If the public choice process leads to this value of $B$ (as it should on efficiency grounds), then, at the margin, the net-wealth effect of government bonds would be zero, despite the continued existence of "imperfect private capital markets." 25

\section{A Government Monopoly in Liquidity Services}

Suppose now that government debt provides a form of "liquidity service" to the holder, in addition to the direct interest payments. Suppose that, at the margin, these services are valued at the amount $L$ per bond per year. Hence, in the context where all individuals have the same discount rate, $r$, an additional perpetual government bond would be evaluated as

$$
B=(i+L) / r \text {. }
$$

The taxes for financing the government debt can be thought of as the interest costs, $i$, plus any costs involved with the process of creating

${ }^{25}$ Of course, government debt issue would be "productive" in a total sense even in the case where the marginal net wealth effect was nil. However, it is this marginal effect which enters into analyses of (marginal) fiscal and monetary policies. 
liquidity services (which could involve the $\gamma$-type costs discussed above). Suppose that $c$ denotes the marginal costs per bond per year associated with the production of liquidity services. Hence, at the margin, the wealth effect of a change in government debt will be

$$
\frac{1}{r}(i+L)-\frac{1}{r}(i+c)=\frac{1}{r}(L-c) .
$$

If the public choice process is such as to motivate the government to act like a competitive producer of liquidity services (as it should on efficiency grounds), then $L=c$ and the marginal-wealth effect of government debt would be nil. On the other hand, if the government operates monopolistically, so that $L>c$, then the marginal-wealth effect of government debt would be positive. ${ }^{26}$ However, it is also possible that the government overextends its production of liquidity services, so that $L<c$ and the marginal-wealth effect of government debt would be negative. This last case corresponds implicitly to the one discussed above in section $I E$, where $L=0$ and $c>0$ were assumed.

Of course, liquidity services can also be provided by private producers. If the types of services rendered by private and public debt instruments are close substitutes, and if the private market is competitive, then governmental monopoly power can arise here only to the extent that, at the margin, the government is more efficient than the private market as a producer of liquidity services. Even if the government is a more efficient producer over a certain range, a sufficient expansion of government "output" would eliminate this efficiency differential at the margin if the production of liquidity services is, at least eventually, subject to increasing marginal costs. As in the case of an imperfect private capital market, as discussed above, the net-wealth effect of government debt depends on the relative efficiency at the margin of government versus private production.

\section{Risk and Asset Substitutability}

The previous sections have dealt with the net-wealth effect of government debt. I have not discussed explicitly in these sections the risk characteristics of government bonds, tax liabilities, and the other types of available assets and liabilities. Tobin (1971, p. 2) has argued: "The calculus of total wealth is less important than the change in the composition of private balance sheets that the government engineers by borrowing from the public-forcing on taxpayers a long-term debt of some uncertainty while providing bond-holders highly liquid and safe assets. Since no one else

${ }^{26}$ Of course, this observation would also apply to government money, which yields a zero rate of explicit interest. The usual real balance effect for outside money assumes that the marginal cost to the government of maintaining real balances is zero, and that the government acts like a monopolist in determining its supply of real balances. 
can perform the same intermediation, the government's debt issues probably do, within limits, augment private wealth. Another way to make the point is to observe that future tax liabilities are likely to be capitalized at a higher discount rate than claims against the government." I have already considered, above, arguments for effectively discounting tax liabilities at a higher rate because of finite lives, imperfect private capital markets, and a government monopoly in the production of liquidity services, and these arguments need not be repeated here. In this part of the paper, I will consider briefly some implications of the risk characteristics of government bonds and of the future tax liabilities associated with the finance of these bonds.

Suppose, first, that there were no uncertainty about the relative burden of the (lump-sum) tax liabilities that finance the government debt. In this situation the uncertainty in an individual's real tax burden associated with government interest payments would reflect solely the variability over time in the real-interest payments themselves. In terms of present values, the variability in the tax liabilities would reflect the variability in prices and interest rates-that is, the same factors which lead to variability in real bond values. In particular, holdings of government debt-amounting to a claim to a certain fraction of total government interest paymentswould be the perfect hedge against variations in tax liabilities. ${ }^{27}$ In this context a simultaneous increase in government interest payments (i.e., government bonds) and in the tax liabilities for financing these payments would not involve any net shift in the risk composition of private balance sheets. ${ }^{28}$

Suppose now that the tax liabilities are subject to an additional variability concerning the relative burden across individuals. Suppose, first, that the variation in relative taxes is purely random, in the sense of being unrelated to variations in relative income, etc. In that case, it is clear that an individual's tax liability associated with government interest payments would be subject to a source of variability above that of the total interest payments. In particular, the fractional holdings of government bonds which corresponds to the expected fraction of tax liabilities would no longer provide a perfect hedge against variations in the tax liabilities. Of course, it would be possible for individuals to utilize private insurance markets to reduce the risks associated with variations in relative tax liability. However, to the extent that insurance arrangements entail transaction costs, the risk associated with relative liability would not generally be fully eliminated. In this case an increase in government bonds would produce a net increase in the risk contained in household balance

${ }^{27}$ I am ignoring here effects which relate to the maturity structure of the government debt. In order to provide a perfect hedge, an individual's holding of debt by maturity would have to correspond to the overall maturity distribution.

28 There could be an effect on individuals who do not hold any government bonds (or assets subject to similar risks). 
sheets-that is, there would be a decline in effective household wealth. The typical household reaction would be twofold: first, an increase in desired total saving, and, second, a shift in portfolio composition away from more risky assets, such as equity capital, and toward less risky assets. The impact on the equity rate of return, and, hence, on capital formation would depend on which of these two responses was the dominant force.

The above discussion would be altered to the extent that variations in tax liability reflect variations in income. In this context the variation in relative tax liabilities can serve to reduce the net variability in disposable income-that is, the income tax works, in part, like a public program of income insurance. If the income-offsetting feature of taxes were the dominant element in relative tax variability, then a shift in government bonds could lead to a reduction in the overall risk contained in household balance sheets. In that case the effects on desired total saving and on portfolio composition would be opposite to those described above. However, it should also be noted that the public program of income insurance which is implied by an income tax system will also involve transaction costs. There are costs associated with administration and with individual reporting effort, as well as "moral hazard" costs associated with incentives for earning income. A full analysis of the wealth effect of government bonds under different tax systems would have to involve a comparison of these types of public transaction costs against the transaction costs associated with the pooling of income risks under private insurance arrangements.

One final observation can be made here. The argument in the early literature for a net-wealth effect of government bonds-for example, that given by Modigliani (1961) - involved a neglect of the tax liabilities associated with the financing of the debt. Similarly, Tobin's argument for effects based on the risk composition of household balance sheets seems to neglect the tax liabilities as an element of these balance sheets. It seems clear that, either in the sense of effects on perceived total wealth, or in the sense of the risk composition of household portfolios, the impact of changes in government debt cannot be satisfactorily analyzed without an explicit treatment of the associated tax liabilities. Once the variability in relative tax liability is considered, there seem to be no clear results concerning the effect of government debt issue on the overall risk contained in household balance sheets. The net effect hinges on the extent to which variations in relative tax liability reflect variations in relative income, and on the transaction costs for public programs of income insurance relative to those of private programs.

\section{Summary and Conclusions}

This paper has focused on the question of whether an increase in government debt constitutes an increase in perceived household wealth. The 
effect of finite lives was examined within the context of an overlappinggenerations model of the economy. It was shown that households would act as though they were infinitely lived, and, hence, that there would be no marginal net-wealth effect of government bonds, so long as there existed an operative chain of intergenerational transfers which connected current to future generations. Net-wealth effects associated with imperfect private capital markets and with a government monopoly in the production of liquidity services were shown to depend on the assumption that the government was more efficient, at the margin, than the private market either in the loan process or in the production of liquidity services. Further, the introduction of government transaction costs for bond issue and tax collection implied that the net-wealth effect of government bonds could be negative. Finally, a consideration of the risk characteristics of government debt and of the tax liabilities associated with the financing of this debt suggested that an increase in government bonds could raise the overall risk contained in household balance sheets. However, this effect depends on the nature of the tax system and on the transaction costs associated with private insurance arrangements.

The basic conclusion is that there is no persuasive theoretical case for treating government debt, at the margin, as a net component of perceived household wealth. The argument for a negative wealth effect seems, a priori, to be as convincing as the argument for a positive effect. Hence, the common assertion (as in Patinkin 1962, chap. 12, p. 289) that the marginal net-wealth effect of government bonds is somewhere between zero and one and is most likely to lie at some positive intermediate value has no a priori foundation. If, in fact, the marginal net-wealth effect were negligible, the implications for monetary and fiscal analysis would be farreaching. In particular, in the case where the marginal net-wealth effect of government bonds is close to zero, (1) the Metzler-type argument for nonneutrality of changes in the stock of outside money would not be valid, (2) a change in the stock of government debt would have no effect on capital formation, and, more generally, (3) fiscal effects involving changes in the relative amounts of tax and debt finance for a given amount of public expenditure would have no effect on aggregate demand, interest rates, and capital formation. ${ }^{29}$

\section{References}

Bailey, M. J. National Income and the Price Level. New York: McGraw-Hill, 1962. Barro, R. J. "The Loan Market, Collateral, and Rates of Interest." Center for Math. Studies in Bus. and Econ., Univ. Chicago, Report 7401, January 1974.

29 The usual fiscal analysis involves a shift in the flow of government debt rather than a one-time shift in the stock. The zero net-wealth effect applies also to the flow case if individuals perceive the implications of the current flow for the future time path of the stock of government debt. 
Becker, G. S. “A Theory of Social Interactions.” J.P.E. 82, no. 6 (November/ December 1974): 1063-93.

Blinder, A. S., and Solow, R. M. "Does Fiscal Policy Matter?" J. Public Econ. 2 (November 1973): 319-37.

Diamond, P. A. "National Debt in a Neoclassical Growth Model." A.E.R. 60 (December 1965): 1126-50.

Hirshleifer, J. "On the Theory of Optimal Investment Decisions." J.P.E. 66, no. 4 (August 1958): 329-52.

Koopmans, T. C. "On the Concept of Optimal Economic Growth." In The Econometric Approach to Development Planning. Amsterdam: North-Holland, 1965.

Metzler, L. "Wealth, Saving, and the Rate of Interest." J.P.E. 59, no. 2 (April 1951): 93-116.

Miller, M. H., and Upton, C. W. Macroeconomics: A Neoclassical Introduction. Homewood, Ill.: Irwin, 1974.

Modigliani, F. "Long-Run Implications of Alternative Fiscal Policies and the Burden of the National Debt." Econ. J. 71 (December 1961) : 730-55.

Mundell, R. "Money, Debt, and the Rate of Interest." In Monetary Theory, edited by R. Mundell. Pacific Palisades, Calif.: Goodyear, 1971.

Patinkin, D. Money, Interest, and Prices. 2d ed. New York: Harper \& Row, 1964.

Peltzman, S. "The Effect of Public Subsidies-in-Kind on Private Expenditures: The Case of Higher Education." J.P.E. 81, no. I (January/February 1973): $1-27$.

Samuelson, P. A. "An Exact Consumption-Loan Model of Interest with or without the Social Contrivance of Money." J.P.E. 66, no. 6 (December 1958): 467-82.

Thompson, E. A. "Debt Instruments in Macroeconomic and Capital Theory." A.E.R. 67 (December 1967) : 1196-1210.

Tobin, J. Essays in Economics. Vol. 1. Macroeconomics. Amsterdam: North-Holland, 1971. 